\title{
Real National Income Average Growth Rate: A Novel Economic Growth and Social Fair Evaluation Index
}

\author{
Chien Wei $\mathrm{Wu}^{1}$ and Wei Zhan Hung ${ }^{2}$ \\ ${ }^{1}$ Department of Economics, National Chi Nan University, No. 1, University Road, Puli, Nantou County 54561, Taiwan \\ ${ }^{2}$ Department of International Tourism and Recreation, Hsing-Kuo University, No. 600, Section 3, Taijiang Boulevard, \\ Annan District, Tainan, Taiwan \\ Correspondence should be addressed to Wei Zhan Hung; steady_2006@hotmail.com
}

Received 4 September 2014; Accepted 12 December 2014

Academic Editor: João Ricardo Faria

Copyright @ 2015 C. W. Wu and W. Z. Hung. This is an open access article distributed under the Creative Commons Attribution License, which permits unrestricted use, distribution, and reproduction in any medium, provided the original work is properly cited.

\begin{abstract}
The purpose of this study is to propose a new economic index, namely, real national income average growth rate (RNIAGR), which measures the performance of economic growth with consideration for income distribution. This study also develops another new economic index, called five-scale real national income average growth rate (FSRNIAGR), which simplifies the calculation of RNIAGR. The merits of these new indexes are discussed to justify their efficacy. This paper also justifies the use of proposed index by showing that this index can actually measure the ordering of social welfare. To highlight the difference between this new index and the traditional ones, this paper compares the index with real economic growth rate using the data of Taiwan. In addition, this paper shows that when the real growth stagnates or even declines, this new index indicates that income distribution deteriorates.
\end{abstract}

\section{Introduction}

In recent years, an immense income disparity has become a common phenomenon across borders. For example, according to a report published by the Organization for Economic Cooperation and Development (OECD) in 2011, the average income of the richest $10 \%$ of the population is about nine times that of the poorest $10 \%$ across the OECD, up from seven times in 1985. Hence, income distribution has been a central concern for both academics and policy makers in developed countries as well as developing countries. As pointed out by Robert Shiller, one of the winners of the Nobel Prize for Economics in 2013, "The most important problem that we are facing now today, I think, is rising inequality in the United States and elsewhere in the world" (The Huffington Post, Oct 15, 2013).

A number of economic indexes are commonly used to measure economic growth and income distribution. For example, real gross domestic product is used to measure economic growth: Gini coefficient, Lorenz curve, and the ratio of income share of highest $20 \%$ to that of lowest $20 \%$ measure income distribution. However, under certain circumstances, these two objectives (growth and distribution) are conflicting to each other. For example, if policy makers focus on pursuing economic growth, this may deteriorate uneven distribution (income gap). By contrast, if they focus on decreasing uneven distribution, this may lower the work incentives of high ability workers.

For policy makers, a single index that incorporates growth as well as distribution may help to immediately crystallize the efficacy of certain policies. Despite the prevalence of many indexes for income inequality, none of the indexes for growth can to some extent reflect the degree of income inequalities. The lack of such index necessitates the study of better indexes that consider growth as well as distribution simultaneously. To this end, this study intends to propose a new index: Real National Income Average Growth Rate (hereafter, RNIAGR). We justify the use of this index by showing that this index can actually measure the ordering of social welfare. In addition, we also show that when the real growth stagnates or even declines, this index indicates that income distribution deteriorates. 
The reminder of this paper is organized as follows. Section 2 reviews major economic growth indexes and income distribution indexes in the existing literature. Section 3 defines the concept of real national income average growth rate, and Section 4 further discusses the advantages of using this new index. In Section 5, using the data in Taiwan, we compare this new index with the usual real economic growth rate. Finally, Section 6 concludes this paper with some remarks.

\section{Economic Index}

2.1. Measuring Economic Growth Index. The main economic index for measuring economic growth is real economic growth rate. The formula of the real economic growth rate is defined as follows:

$$
\left(\frac{\text { Real GDP }}{\text { Real GDP }_{t-1}}\right)-1
$$

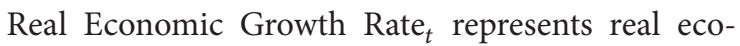
nomic growth rate of $t$ th year.

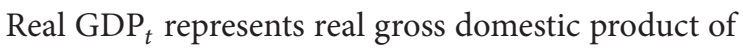
$t$ th year.

Real GDP $\mathrm{GD}_{t-1}$ represents real gross domestic product of $t-1$ th year.

Gross domestic product can be explained as the power of the country. Positive real economic growth rate means the power of the country is increasing. It seems every country aims to promote their real economic growth rate.

Real economic growth rate is calculated as the total income of all nationals in the last year divided by the total net increase income of all nationals in this year. It can reveal the macroeconomic level of the entire nation, but it does not display the information of the income growth rate of each individual nation. However, promoting real economic growth rate usually leads to a side effect: unequal income distribution $[1,2]$.

2.2. Measuring Income Distribution Index. The main economic index for measuring income distribution includes Lorenz curve, Gini coefficient, and ratio of income share of highest $20 \%$ to that of lowest $20 \%$.

Lorenz curve is an income aggregation curve which aggregates income from the lowest income national to the highest income national [3].

The Gini coefficient is a measuring index of statistical dispersion formulated by Corrado Gini [4]. Gini coefficient is usually defined mathematically based on the Lorenz curve. Gini coefficient ranges from 0 to 1 . A low Gini coefficient indicates a more equal distribution. Gini coefficient $=0$ represents complete equality. Higher Gini coefficients indicate more unequal distribution. Gini coefficient $=1$ represents complete inequality. Although Gini coefficient can explain the unequal degree of income distribution, it is useless to use Gini coefficient to express the financial net increase income distribute of each national in each year.
As implied by the name, ratio of income share of highest $20 \%$ to that of lowest $20 \%$ means the total income of nationals whose income rank is in lowest $20 \%$ divides the total income of nationals whose income rank is in highest $20 \%$ [5]. The drawback of ratio of income share of highest $20 \%$ to that of lowest $20 \%$ is that it does not consider the income distribution of nationals whose income is in the middle.

\section{Real National Income Average Growth Rate}

To consider economic growth and income distribution simultaneous, this research provides a new index-real national income average growth rate. The concept of RNIAGR is averaged real income growth of each individual national. Unlike real economic growth rate that calculates the economic growth rate based on the total income of all nationals in previous year, RNIAGR is calculated from individual income growth rate based on individual income in the previous year and average of all of individual income growth rate. RNIAGR can reflect the average income growth status of individual national. This formula supposes that the volume of nationals in $t$ th year and in $t-1$ th year in the same Country is the same:

$$
\operatorname{RNIAGR}_{t}=\frac{1}{p} * \sum_{j=1}^{p}\left(\frac{I_{j t}}{I_{j t-1} *\left(1+F_{t}\right)}\right)-1 .
$$

RNIAGR $_{t}$ represents real national income average growth rate in $t$ th year.

$I_{j t}$ represents the income of $j$ th national in $t$ th year.

$I_{j t-1}$ represents the income of $j$ th national in $t-1$ th year.

$F_{t}$ represents the inflation rate in $t$ th year.

$P$ represents the volume of nationals in the country.

Using Figure 1 as example, $x$-axis represents the rank of income from low income national to high income national. Point $A$ represents the lowest income national and point $B$ represents the highest income national. From point $A$ to point $B$, all of the points can reflect an income of one national.

If Area $A B C$ represents the total income of all nationals in last year, Area $A C D$ represents the net increase income of all nationals in this year. So, nominal economic growth rate can be represented as Area $A B C$ divides Area $A C D$. From point $A$ to point $B$, all of the points can reflect an income of one national. Every national uses the individual income as a base to calculate the individual income growth rate. And we can obtain nominal national income average growth by averaging the individual income growth rate. For example, point $i$ that is between point $A$ and point $B$ represents $i$ th national. The income of $i$ th national in last year is line $\overline{i j}$. The net increase income of $i$ th national in this year is line $\overline{j k}$. The individual income growth rate of $i$ th national is line $\overline{i j}$ divide line $\overline{j k}$. In order to reflect the real income status of each national, nominal national income average growth needs to be divided by inflation rate of this year to acquire real national income average growth rate of this year. 


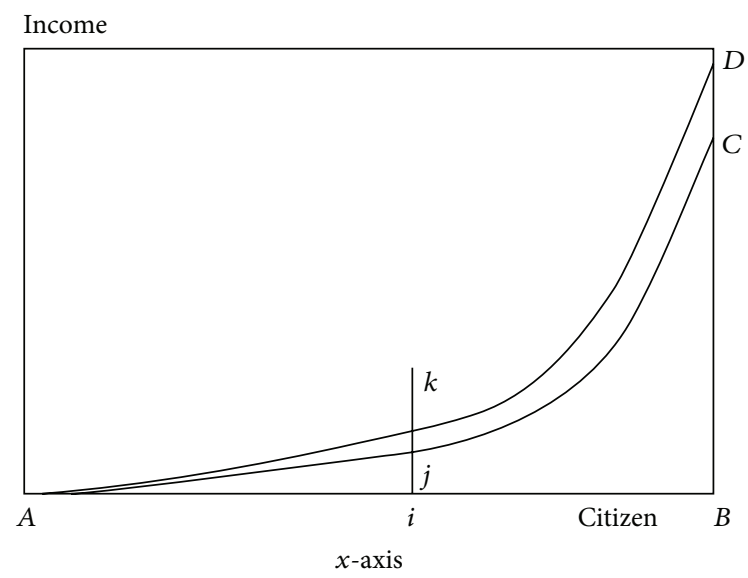

FIGURE 1: National income distribution diagram. Notice: the order of the citizens at axis " $x$ " can (and probably will) change from one year to another.

Because it is not easy and is too complex to acquire income information of each individual, this study presents other new indexes-five-scale real national income average growth rate (FSRNIAGR) which can roughly represent real national income average growth rate. FSRNIAGR can reduce the calculation complexity without losing the meaning of RNIAGR. First, we divide the entire nationals into 5 scales. And then, we aggregate the income of each national in each scale in the last year and aggregate the net increase income of each national in each scale in this year. In each scale, the aggregated income of each national in these scales in the last year divides the aggregated net increase income of each national in these scales in this year as nominal national income average growth rate in each scale. Finally, nominal five-scale national income average growth rates are acquired by averaging nominal national income average growth rate in each scale. In order to reflect the real income status of each national, nominal five-scale national income average growth needs to be divided by inflation rate of this year to acquire real five-scale national income average growth rate of this year (Figure 2):

FSRNIAGR $_{t}$

$$
\begin{gathered}
=\left(\sum_{i=1}^{5}\left(\frac{\sum_{j=\left(p_{t} / 5\right) *(i-1)+1}^{\left(p_{t} / 5\right) * i} I_{j t}}{\sum_{j=\left(p_{t-1} / 5\right) *(i-1)+1}^{\left(p_{t-1} / 5\right) I_{j t-1}}}\right)\right. \\
\left.* \frac{\left(P_{t-1} / P_{t}\right)}{\left(1+F_{t}\right)}\right) \times(5)^{-1}-1 .
\end{gathered}
$$

FSRNIAGR $_{t}$ represents five-scale real national income average growth rate of $t$ th year.

$I_{j t}$ represents the ordered income of $j$ th national in $t$ th year.

$I_{j t-1}$ represents the ordered income of $j$ th national in $t-1$ th year.

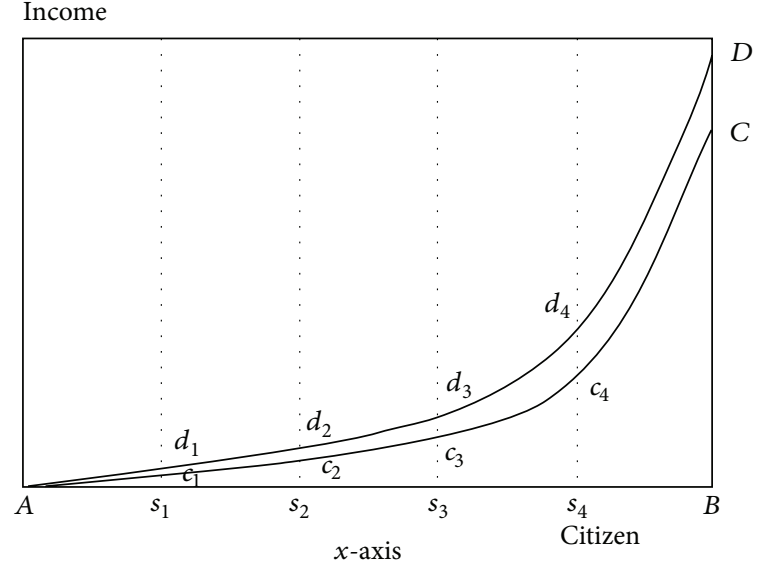

FIgURE 2: Five-scale national income distribution diagram.

$F_{t}$ represents the inflation rate in $t$ th year.

$p_{t}$ represents the volume of nationals in the Country in $t$ th year.

$p_{t-1}$ represents the volume of nationals in the Country in $t-1$ th year.

$\left(p_{t} / 5\right) *(i-1)$ represents the lower bound of national in $i$ th scale in $t$ th year.

$\left(p_{t-1} / 5\right) *(i-1)$ represents the lower bound of national in $i$ th scale in $t-1$ th year.

$\left(p_{t} / 5\right) * i$ represents the upper bound of national in $i$ th scale in $t$ th year.

$\left(p_{t-1} / 5\right) * i$ represents the upper bound of national in $i$ th scale in $t-1$ th year.

Because the volume of nationals in $t$ th year and in $t-1$ th year in the same Country is different, FSRNIAGR ${ }_{t}$ must be adjusted by $\left(P_{t-1} / P_{t}\right)$ for acquiring the rational growth rate.

In reality, the variance of income for each national between each year is not always positive and the nationals of the country are not usually adjusted their income according to their income in the previous year. So, $I_{j t-1}$ represents the income of national whose financial rank is $j$ th in $t-1$ th year and $I_{j t}$ represents the income of national whose financial rank is $j$ th in $t$ th year.

Using Figure 2 as an example, $x$-axis represents the rank of income from low income national to high income national. Point $A$ represents the lowest income national and point $B$ represents the highest income national. Line $\overline{A s_{1}}, \overline{s_{1} s_{2}}$, $\overline{s_{2} s_{3}}, \overline{s_{3} s_{4}}, \overline{s_{4} B}$ represents national sets. The national whose income is classified as the same income scale is in the same national set. Line $\overline{A s_{1}}$ represents the nationals whose income is ranking in lowest $20 \%$. Line $\overline{s_{1} s_{2}}$ represents the nationals whose income is ranking between lowest $20 \%$ and lowest $40 \%$. Line $\overline{s_{2} s_{3}}$ represents the nationals whose income is ranking between lowest $40 \%$ and lowest $60 \%$. Line $\overline{s_{3} s_{4}}$ represents the nationals whose income is ranking between highest $20 \%$ and highest $40 \%$. Line $\overline{s_{4} B}$ represents the nationals whose income is ranking in highest $20 \%$. 
Area $A s_{1} c_{1}$ represents the total income of the nationals whose income is ranking in lowest $20 \%$ in the last year; Area $A s_{1} d_{1}$ represents the total income of the nationals whose income is ranking in lowest $20 \%$ in this year. Area $s_{1} c_{1} c_{2} s_{2}$ represents the total income of the nationals whose income is ranking between lowest $20 \%$ and lowest $40 \%$ in the last year, Area $s_{1} d_{1} d_{2} s_{2}$ represents the total income of the nationals whose income is ranking between lowest $20 \%$ and lowest $40 \%$ in this year and suchlike.

So, nominal income growth rate of nationals whose income is ranking in lowest $20 \%$ can be represented as Area $A s_{1} c_{1}$ divides Area $A s_{1} d_{1}-1$. Nominal income growth rate of nationals whose income is ranking between lowest $20 \%$ and lowest $40 \%$ can be represented as Area $s_{1} c_{1} c_{2} s_{2}$ divides Area $s_{1} d_{1} d_{2} s_{2}-1$ and the like.

Five-scale real national income average growth rate (FSRNIAGR) of $t$ th year can be presented as follows:

FSRNIAGR $_{t}$

$$
\begin{aligned}
& =\left(\left(\frac{A\left(A s_{1} d_{1}\right)}{A\left(A s_{1} c_{1}\right)}+\frac{A\left(s_{1} d_{1} d_{2} s_{2}\right)}{A\left(s_{1} c_{1} c_{2} s_{2}\right)}+\frac{A\left(s_{2} d_{2} d_{3} s_{3}\right)}{A\left(s_{2} c_{2} c_{3} s_{3}\right)}\right.\right. \\
& \left.\left.\quad+\frac{A\left(s_{3} d_{3} d_{4} s_{4}\right)}{A\left(s_{3} c_{3} c_{4} s_{4}\right)}+\frac{A\left(s_{4} d_{4} D B\right)}{A\left(s_{4} c_{4} C B\right)}\right) * \frac{\left(P_{t-1} / P_{t}\right)}{\left(1+F_{t}\right)}\right) \\
& \quad \times(5)^{-1}-1 .
\end{aligned}
$$

$A\left(A s_{1} d_{1}\right)$ represents the total income of nationals whose income is ranking in lowest $20 \%$ in $t$ th year.

$A\left(A s_{1} c_{1}\right)$ represents the total income of nationals whose income is ranking in lowest $20 \%$ in $t-1$ th year.

$A\left(s_{1} d_{1} d_{2} s_{2}\right)$ represents the total income of nationals whose income is ranking between lowest $20 \%$ and lowest $40 \%$ in $t$ th year.

$A\left(s_{1} c_{1} c_{2} s_{2}\right)$ represents the total income of nationals whose income is ranking between lowest $20 \%$ and lowest $40 \%$ in $t-1$ th year.

$A\left(s_{2} d_{2} d_{3} s_{3}\right)$ represents the total income of nationals whose income is ranking between lowest $40 \%$ and lowest $60 \%$ in $t$ th year.

$A\left(s_{2} c_{2} c_{3} s_{3}\right)$ represents the total income of nationals whose income is ranking between lowest $40 \%$ and lowest $60 \%$ in $t-1$ th year.

$A\left(s_{3} d_{3} d_{4} s_{4}\right)$ represents the total income of nationals whose income is ranking highest $20 \%$ and highest $40 \%$ in $t$ th year.

$A\left(s_{3} c_{3} c_{4} s_{4}\right)$ represents the total income of nationals whose income is ranking between highest $20 \%$ and highest $40 \%$ in $t-1$ th year.

$A\left(s_{4} d_{4} D B\right)$ represents the total income of nationals whose income is ranking in highest $20 \%$ in $t$ th year.

$A\left(s_{4} c_{4} C B\right)$ represents the total income of nationals whose income is ranking in highest $20 \%$ in $t-1$ th year.

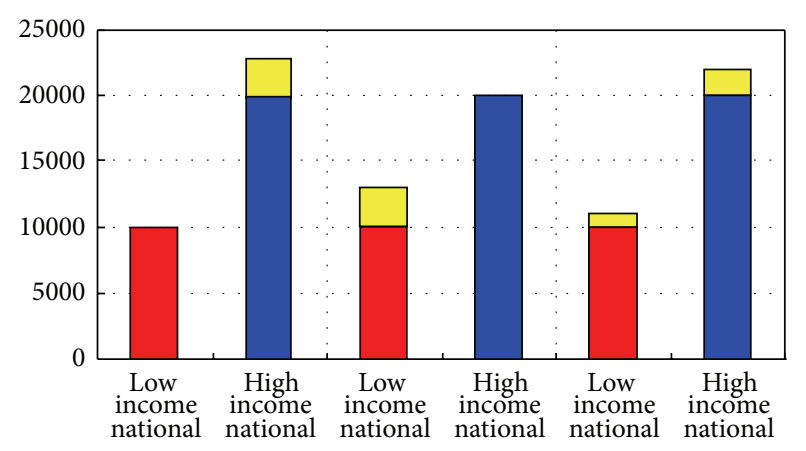

FIgURE 3: National income example.

In order to reflect the real income status of each national, five-scale nominal national income average growth rate needs to be divided by inflation rate of this year to acquire five-scale real national income average growth rate of this year.

\section{The Merits of the Real National Income Average Growth Rate}

The strong point of real national income average growth rate is that it can modify the drawback of real economic growth rate which did not consider income distribution.

For example, we suppose that there exists a country who possesses two nationals. The income of one national is 20,000 US dollars in last year (blue color area), and the income of the other national is 10,000 US dollars in last year (red color area). Suppose that gross domestic product increases 3,000 US this year. The inflation rate of this year is $2 \%$.

So, the real economic growth rate in this country is $((20,000+10,000+3,000) /(20,000+10,000)) /(1+2 \%)-$ $1=7.8 \%$.

Case 1 (all additional income is acquired by the rich individual). If all the economic profit is acquired by higher national, the real national income average growth rate is $(0.5 *$ $(10000 / 10000)+0.5 *(23000 / 20000)) /(1+2 \%)-1=5.4 \%$.

Case 2 (all additional income is acquired by the poor individual). If all the economic profit is acquired by lower national, the real national income average growth rate is $0.5 *$ $(13000 / 10000)+0.5 *(20000 / 20000)-1=12.7 \%$.

Case 3 (all additional income is acquired by each individual and the additional income is distributed according to the previous income of each individual). If economic profit is distributed according to the income of each national last year, the real national income average growth rate is $(0.5 *$ $(11000 / 10000)+0.5 *(22000 / 20000)) /(1+2 \%)-1=7.8 \%$. (Refer to Figure 3).

When the level of unequal income distribution is lower, real national income average growth rate (12.7\%) is larger than real economic growth rate $(7.8 \%)$. Otherwise, real national income average growth rate $(5.4 \%)$ is larger than real economic growth rate $(7.8 \%)$ when the level of unequal 
TABLE 1: The relation of real economic growth rate, real national income average growth rate, and income distribution.

\begin{tabular}{|c|c|c|c|}
\hline & \multicolumn{2}{|c|}{ Real economic growth rate } \\
\hline & & Increase & Decrease \\
\hline \multirow{2}{*}{$\begin{array}{l}\text { The level of } \\
\text { unequal } \\
\text { income } \\
\text { distribution }\end{array}$} & Increase & $\begin{array}{c}\text { RNIAGR is } \\
\text { increasing and } \\
\text { adjusted to lower } \\
\text { down }\end{array}$ & $\begin{array}{c}\text { RNIAGR is } \\
\text { decreasing and } \\
\text { adjusted to lower } \\
\text { down more. }\end{array}$ \\
\hline & Decrease & $\begin{array}{l}\text { RNIAGR is } \\
\text { increasing and } \\
\text { adjusted to be } \\
\text { promoted }\end{array}$ & $\begin{array}{l}\text { RNIAGR is } \\
\text { decreasing and } \\
\text { adjusted to } \\
\text { promote a few. }\end{array}$ \\
\hline
\end{tabular}

income distribution is rising. So, government will get a better performance in real national income average growth rate (relative to real economic growth rate) when government policy can promote the income of lower income national largely.

Real national income average growth rate not only can be positive in relation to real economic growth rate but also can adjust real economic growth rate according to the condition of the level of unequal income distribution. For the relation of real economic growth rate, real national income average growth rate, and income distribution, refer to Table 1 .

\section{Social Welfare Function}

To give further rationale for this new index RNIAGR, we set up a simple model to illustrate the relationship of real national income average growth rate and some total social welfare function.

We assume that each national has the same increasing utility function of income $U(I)=\ln (I)$ with a diminishing marginal utility. Further, we assume that the total social welfare function is simply the summation of all nationals' utility function $\sum_{i=1}^{p} U\left(I_{i, t}\right)$, where $\left(I_{1, t}, I_{2, t}, \ldots, I_{p, t}\right)$ is the income distribution of all nationals at time $t$.

We consider an income distribution $I_{t-1}=\left(I_{1, t-1}, I_{2, t-1}\right.$, $\left.\ldots, I_{p, t-1}\right)$ at time $t-1$, and two possible income distributions $I_{t}=\left(I_{1, t}, I_{2, t}, \ldots, I_{p, t}\right)$ and $I_{t}^{\prime}=\left(I_{1, t}^{\prime}, I_{2, t}^{\prime}, \ldots, I_{p, t}^{\prime}\right)$ at time $t$. We also assume that the difference of income between time $t$ and time $t-1$ is relatively small; that is, $I_{i, t}-I_{i, t-1} \ll I_{i, t-1}$ and $I_{i, t}^{\prime}-$ $I_{i, t-1} \ll I_{i, t-1}$, for $i=1,2, \ldots, p$. Let $\Delta U_{j, t} \equiv U\left(I_{j, t}\right)-U\left(I_{j, t-1}\right)$ and $\Delta U_{j, t}^{\prime} \equiv U\left(I_{j, t}^{\prime}\right)-U\left(I_{j, t-1}\right)$. Therefore, the difference of the social welfare between two possible incomes is

$$
\begin{aligned}
\sum & U\left(I_{j, t}\right)-\sum U\left(I_{j, t}^{\prime}\right) \\
& =\sum\left[U\left(I_{j, t-1}\right)+\Delta U_{i, t}\right]-\sum\left[U\left(I_{j, t-1}\right)+\Delta_{j, t}^{\prime}\right] \\
& =\sum \Delta U_{j, t}-\sum \Delta U_{j, t}^{\prime} .
\end{aligned}
$$

For a small change in $I$, we might take $(\partial / \partial I) U(\cdot) d I$ as the approximation to the resulting change in $U$, knowing that the smaller the $d I$, the better the approximation. Therefore, $\sum \Delta U_{j, t} \approx \sum(\partial / \partial I) U\left(I_{j, t-1}\right) * d I_{j}$ and $\sum \Delta U_{j, t}^{\prime} \approx$ $\sum(\partial / \partial I) U\left(I_{j, t-1}\right) * d I_{j}^{\prime}$, where $d I_{j}=I_{j, t}-I_{j, t-1}$ and $d I_{j}^{\prime}=I_{j, t}^{\prime}-I_{j, t-1}$. We then define an approximation of $\sum U\left(I_{j, t}\right)-\sum U\left(I_{j, t}^{\prime}\right)$ to be

$$
\begin{aligned}
& {\left[\sum U\left(I_{j, t}\right)-\sum U\left(I_{j, t}^{\prime}\right)\right]^{a}} \\
& \quad \equiv \sum \frac{\partial}{\partial I} U\left(I_{j, t-i}\right) * d I-\sum \frac{\partial}{\partial I} U\left(I_{j, t-1}\right) d I_{j}^{\prime} \\
& \quad=\sum \frac{d I_{j}-d I_{j}^{\prime}}{I_{j, t-1}} .
\end{aligned}
$$

We are now ready to state the following proposition.

Proposition 1. Consider the following

$$
\begin{aligned}
& \operatorname{RNIAGR}\left(I_{t}\right)-\operatorname{RNIAGR}\left(I_{t}^{\prime}\right) \\
& \quad \geq 0<==>\left[\sum U\left(I_{j, t}\right)-\sum U\left(I_{j, t}^{\prime}\right)\right]^{a} \geq 0 .
\end{aligned}
$$

Proof. Consider the following

$$
\begin{aligned}
\operatorname{RNIAGR}\left(I_{t}\right)-\operatorname{RNIAGR}\left(I_{t}^{\prime}\right) \\
=\left\{\frac{1}{P} \sum\left(\frac{I_{j, t}}{I_{j, t-1} *\left(1+F_{t}\right)}\right)-1\right\} \\
-\left\{\frac{1}{P} \sum\left(\frac{I_{j, t}^{\prime}}{I_{j, t-1} *\left(1+F_{t}\right)}\right)-1\right\} \\
=\frac{1}{P\left(1+F_{t}\right)}\left(\sum \frac{I_{j, t}}{I_{j, t-1}} \sum \frac{I_{j, t}^{\prime}}{I_{j, t-1}}\right) \\
=\frac{1}{P\left(1+F_{t}\right)}\left(\sum \frac{I_{j, t}-I_{j, t}^{\prime}}{I_{j, t-1}}\right) \\
=\frac{1}{P\left(1+F_{t}\right)}\left(\sum \frac{\left(I_{j, t}-I_{j, t-1}\right)-\left(I_{j, t}^{\prime}-I_{j, t-1}\right)}{I_{j, t-1}}\right) \\
=\frac{1}{P\left(1+F_{t}\right)}\left(\sum \frac{d I_{j}-d I_{j}^{\prime}}{I_{j, t-1}}\right) .
\end{aligned}
$$

Since both $P$ and $\left(1+F_{t}\right)$ are bigger than zero, it is obvious that $\operatorname{RNIAGR}\left(I_{t}\right)-\operatorname{RNIAGR}\left(I_{t}^{\prime}\right) \geq 0<==>\left[\sum U\left(I_{j, t}\right)-\right.$ $\left.\sum U\left(I_{j, t}^{\prime}\right)\right]^{a} \geq 0$.

With the above proposition, we could use the RNIAGR as an approximation of social welfare.

\section{Examples}

To explain the usefulness of real national income average growth rate, this study uses Taiwan's data as an example to compare the result of real economic growth rate and real national income average growth rate. The data about real GDP, nominal GDP, five-scale disposable incomes, consumer price index, and Gini index are collected from Taiwan's government [6]. Inflation rate is represented by consumer 
TABLE 2: The comparison result of real economic growth rate and real national income average growth rate in Taiwan.

\begin{tabular}{|c|c|c|c|c|c|c|c|c|}
\hline \multirow[b]{2}{*}{ Year } & \multicolumn{5}{|c|}{ National income growth rate based on different equal divisions of recipients } & \multirow[b]{2}{*}{$\begin{array}{l}\text { Real national } \\
\text { income } \\
\text { average } \\
\text { growth rate }\end{array}$} & \multirow[b]{2}{*}{$\begin{array}{l}\text { Real economic } \\
\text { growth rate }\end{array}$} & \multirow[b]{2}{*}{ Gini Index } \\
\hline & $\begin{array}{l}\text { The national } \\
\text { whose income } \\
\text { rank is in } \\
\text { lowest } 20 \%\end{array}$ & $\begin{array}{c}\text { The national } \\
\text { whose income } \\
\text { rank is } \\
\text { between } \\
\text { lowest } 20 \% \\
\text { and lowest } \\
40 \%\end{array}$ & $\begin{array}{c}\text { The national } \\
\text { whose income } \\
\text { rank is } \\
\text { between } \\
\text { lowest } 40 \% \\
\text { and lowest } \\
60 \%\end{array}$ & $\begin{array}{c}\text { The national } \\
\text { whose income } \\
\text { rank is } \\
\text { between } \\
\text { highest } 20 \% \\
\text { and highest } \\
40 \%\end{array}$ & $\begin{array}{l}\text { The national } \\
\text { whose income } \\
\text { rank is in } \\
\text { highest } 20 \%\end{array}$ & & & \\
\hline 1995 & $6.24 \%$ & $1.50 \%$ & $-0.77 \%$ & $-1.57 \%$ & $-0.17 \%$ & $1.05 \%$ & $0.03 \%$ & 0.317 \\
\hline 1996 & $-3.62 \%$ & $-3.46 \%$ & $-3.32 \%$ & $-2.20 \%$ & $-3.13 \%$ & $-3.15 \%$ & $-3.03 \%$ & 0.317 \\
\hline 1997 & $4.44 \%$ & $2.16 \%$ & $1.22 \%$ & $0.50 \%$ & $1.46 \%$ & $1.95 \%$ & $1.49 \%$ & 0.320 \\
\hline 1998 & $2.65 \%$ & $1.68 \%$ & $0.25 \%$ & $0.78 \%$ & $1.46 \%$ & $1.36 \%$ & $1.21 \%$ & 0.324 \\
\hline 1999 & $0.60 \%$ & $1.97 \%$ & $1.96 \%$ & $0.93 \%$ & $0.48 \%$ & $1.19 \%$ & $1.03 \%$ & 0.325 \\
\hline 2000 & $1.73 \%$ & $1.79 \%$ & $0.27 \%$ & $0.78 \%$ & $-0.72 \%$ & $0.77 \%$ & $0.28 \%$ & 0.326 \\
\hline 2001 & $-8.93 \%$ & $-8.33 \%$ & $-5.70 \%$ & $-3.63 \%$ & $2.19 \%$ & $-4.88 \%$ & $-2.64 \%$ & 0.350 \\
\hline 2002 & $1.41 \%$ & $0.53 \%$ & $-0.34 \%$ & $-1.33 \%$ & $-1.02 \%$ & $-0.15 \%$ & $-0.62 \%$ & 0.345 \\
\hline 2003 & $3.71 \%$ & $2.94 \%$ & $1.96 \%$ & $1.66 \%$ & $0.24 \%$ & $2.10 \%$ & $1.42 \%$ & 0.343 \\
\hline 2004 & $1.57 \%$ & $1.15 \%$ & $2.29 \%$ & $2.16 \%$ & $1.39 \%$ & $1.71 \%$ & $1.70 \%$ & 0.338 \\
\hline 2005 & $-0.01 \%$ & $0.51 \%$ & $-1.17 \%$ & $-1.21 \%$ & $-1.27 \%$ & $-0.63 \%$ & $-0.93 \%$ & 0.340 \\
\hline 2006 & $-2.61 \%$ & $-2.50 \%$ & $-1.20 \%$ & $-0.23 \%$ & $-1.59 \%$ & $-1.63 \%$ & $-1.41 \%$ & 0.339 \\
\hline 2007 & $0.47 \%$ & $0.82 \%$ & $-0.25 \%$ & $-0.91 \%$ & $0.59 \%$ & $0.14 \%$ & $0.13 \%$ & 0.340 \\
\hline 2008 & $-0.83 \%$ & $-4.48 \%$ & $-4.49 \%$ & $-2.71 \%$ & $-1.78 \%$ & $-2.85 \%$ & $-2.70 \%$ & 0.341 \\
\hline 2009 & $-8.78 \%$ & $-5.91 \%$ & $-5.04 \%$ & $-6.04 \%$ & $-6.02 \%$ & $-6.36 \%$ & $-6.06 \%$ & 0.345 \\
\hline 2010 & $4.81 \%$ & $4.15 \%$ & $4.03 \%$ & $3.94 \%$ & $2.43 \%$ & $3.87 \%$ & $3.42 \%$ & 0.342 \\
\hline 2011 & $-3.58 \%$ & $-2.79 \%$ & $-3.56 \%$ & $-3.44 \%$ & $-1.35 \%$ & $-2.94 \%$ & $-2.53 \%$ & 0.342 \\
\hline
\end{tabular}

price index. The unit of data is 1 year. The range of data is between 1995 and 2011. To compare the results of real economic growth rate and real national income average growth rate, refer to Table 2 and Figure 4.

As indicated by Taiwan's economic data, the real economic growth rate had been lower than $2 \%$ since 1995, except for the $3.64 \%$ in 2010 . Seven out of sixteen years had seen negative growth. The rates of growth in 2001, 2008, 2009, and 2011 were all worse than $-2 \%$.

Real national income average growth rate can adjust real economic growth rate based on the real growth situation of citizen group. For example, the real economic growth rate of Taiwan in 1995 is only $0.03 \%$. Real income growth rate of the national whose income is ranking in lowest $20 \%$ is $6.24 \%$, real income growth rate of the national whose income is ranking between lowest $20 \%$ and lowest $40 \%$ is $1.50 \%$. Real national income average growth rate is $1.05 \%$. Although the real economic growth rate does not increase, real national income average growth rate also can acquire high performance if the unequal income distribution is improved.

In 2001, the real economic growth rate was $-2.64 \%$ for Taiwan. However, the negative growth was more than 3.5\% for individuals at lower $80 \%$ income brackets, and the individuals at lower $40 \%$ income brackets saw a negative growth amounting to more than $8 \%$. But, people in the top $20 \%$ saw their income growing by $2.19 \%$. Not only the real economic growth decrease but also the unequal income distribution got worse, so real national income average growth rate is $-4.88 \%$ which is lower than real economic growth rate. The Gini index also got worse in this year $(0.350>0.326)$ (the higher Gini index, the more unequal in income distribution).

In 2010, after the poor performance in 2009, the real economic growth rate was $3.42 \%$ for Taiwan. Because the positive growth was higher than $3.42 \%$ for individuals at lower $80 \%$ income brackets and people in the top $20 \%$ only saw their income growing by $2.43 \%$, real national income average growth rate is $3.87 \%$ which is higher than real economic growth rate (3.42\%). In reality, the Gini index also got better in this year $(0.342<0.345)$. The economic was performing well in this year because not only the economic got better but also the unequal income distribution had been improved.

The Gini index is defined based on the concept of stock because this index is determined according to the long term income ability of each national. The real national income average growth rate is developed by using the concept of flow because this index is generated by applying the data of individual national income in this year. So, the real national income average growth rate reflects the practical phenomena of economic more frequently than Gini index. For example, the unequal income distribution got worse quickly in Taiwan in 2001 so Gini index increased from 0.326 to 0.350 , But Gini index decreased slowly in 2002 2004 when the unequal income distribution had been improved. 


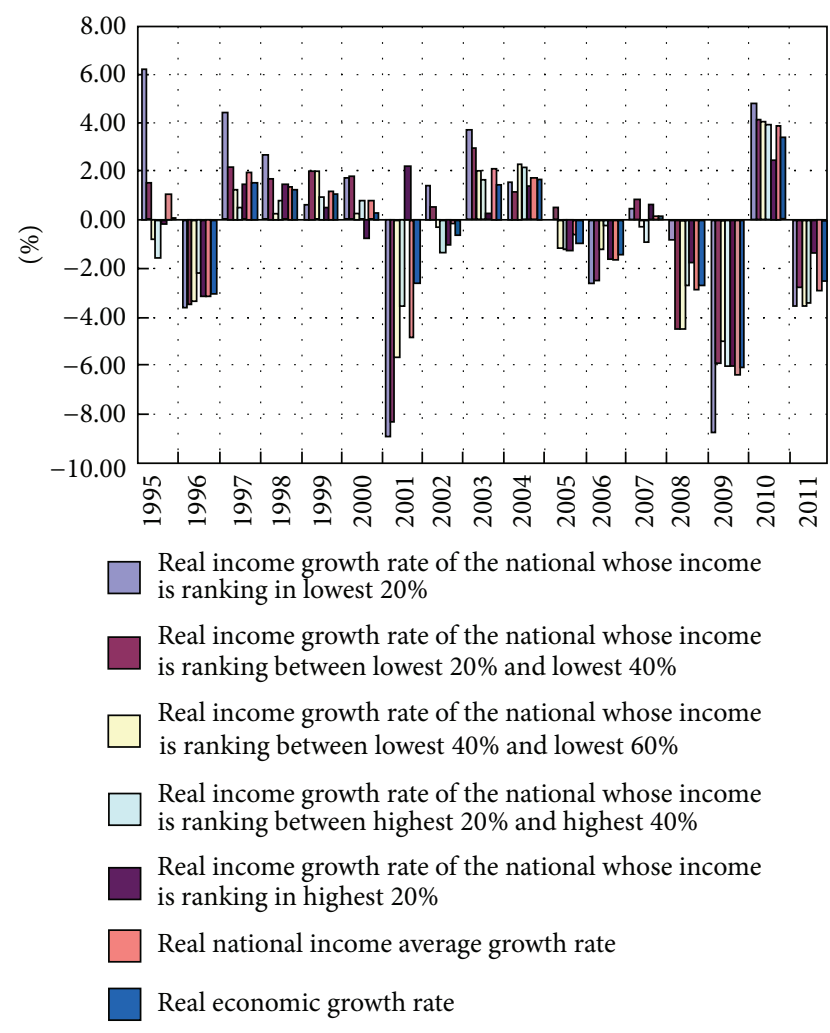

FIGURE 4: The comparison result of real economic growth rate and real national income average growth rate in Taiwan.

There is an interesting phenomenon that occurred in Taiwan: real national income average growth rate usually performed better than real economic growth rate when the real economic growth rate was positive. On the other hand, real national income average growth rate usually performs worse than real economic growth rate when the real economic growth rate is negative.

\section{Conclusion and Future Research}

In this study, we develop a new economic index-RNIAGR for describing economic situation which considers economic growth and income distribution simultaneous. Proposed index not only can reflect real economic growth rate but also can adjust real economic growth rate according to the condition of the level of unequal income distribution. In order to lower down calculation complexity, this research also develops an economic index-FSRNIAGR, which can simplify calculation process without losing the meaning of RNIAGR.

The reason of choosing FSRNIAGR is that the index of FSRNIAGR can be generated by five-scale disposable income which is easy to be acquired in the website in each government.

In the future, some economic numerical data will be collected and the economic performance comparison of each country based on proposed index will be discussed. The sensitivity analysis in relation to the arbitrary number of classes which is used to classify the group of income distribution will be done by the simulation according to the practical income distribution of each country.

\section{Conflict of Interests}

The authors declare that there is no conflict of interests regarding the publication of this paper.

\section{References}

[1] R. Kanbur, "Chapter 13 Income distribution and development," Handbook of Income Distribution, vol. 1, pp. 791-841, 2000.

[2] R. Kanbur, "Economic policy, distribution and poverty: the nature of disagreements," World Development, vol. 29, no. 6, pp. 1083-1094, 2001.

[3] V. Fakoor, M. B. Ghalibaf, and H. A. Azarnoosh, "Asymptotic behaviors of the Lorenz curve and Gini index in sampling from a length-biased distribution," Statistics and Probability Letters, vol. 81, no. 9, pp. 1425-1435, 2011.

[4] B. Milanovic, "A simple way to calculate the Gini coefficient, and some implications," Economics Letters, vol. 56, no. 1, pp. 45-49, 1997.

[5] R. Anderton, Macroeconomic Performance in a Globalising Economy, Cambridge University Press, Cambridge, UK, 2010.

[6] Dorectorate-General of Budget, Accounting and Statistics of Executive Yuan, Taiwan, http://www.dgbas.gov.tw. 

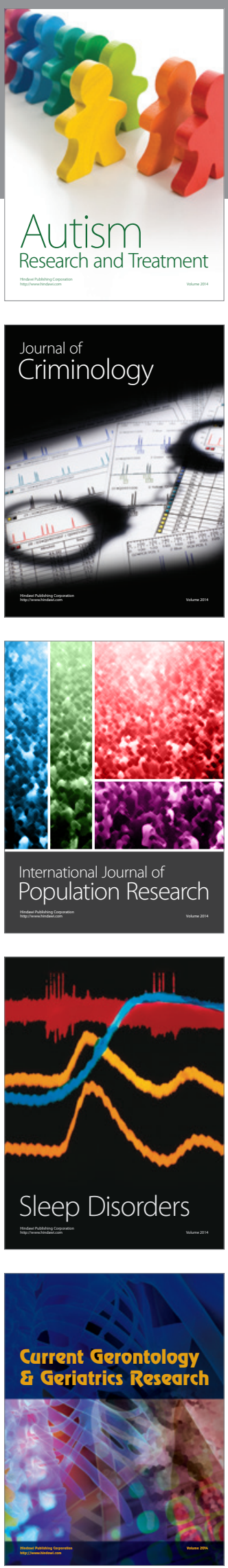
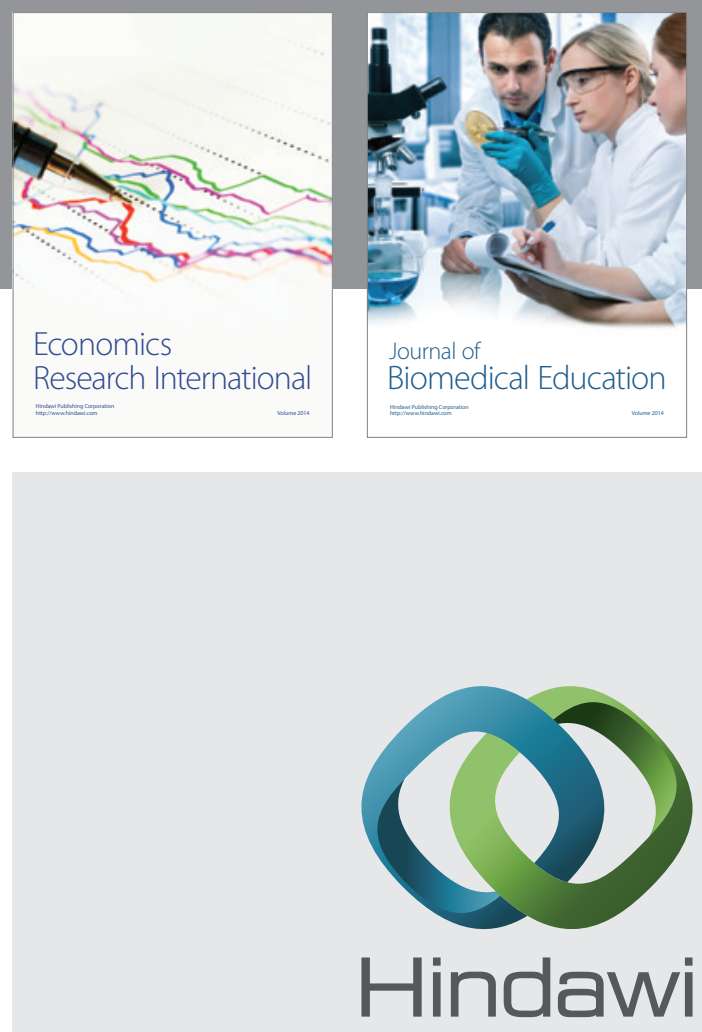

Submit your manuscripts at

http://www.hindawi.com
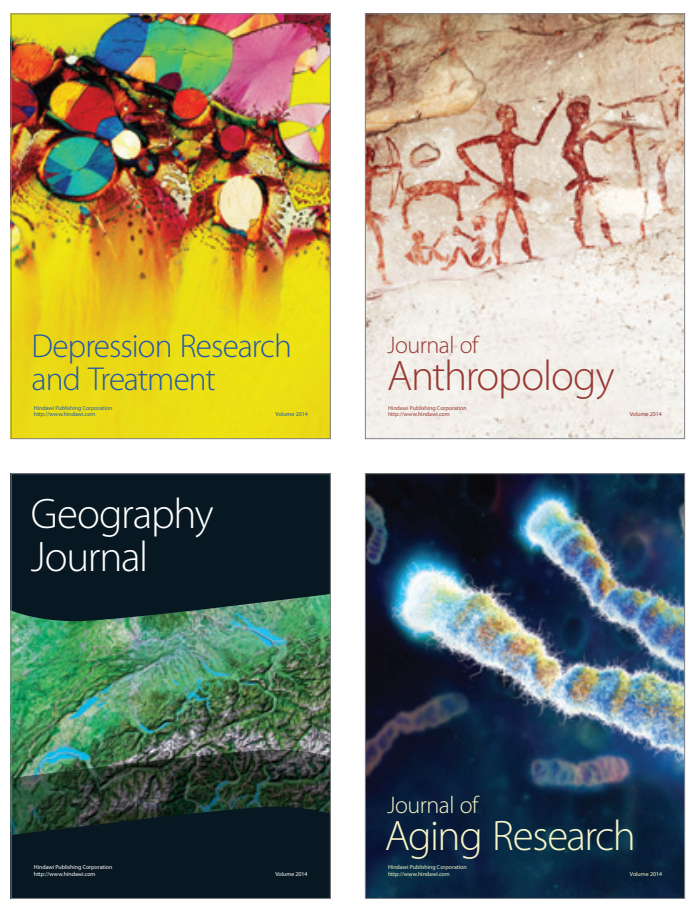
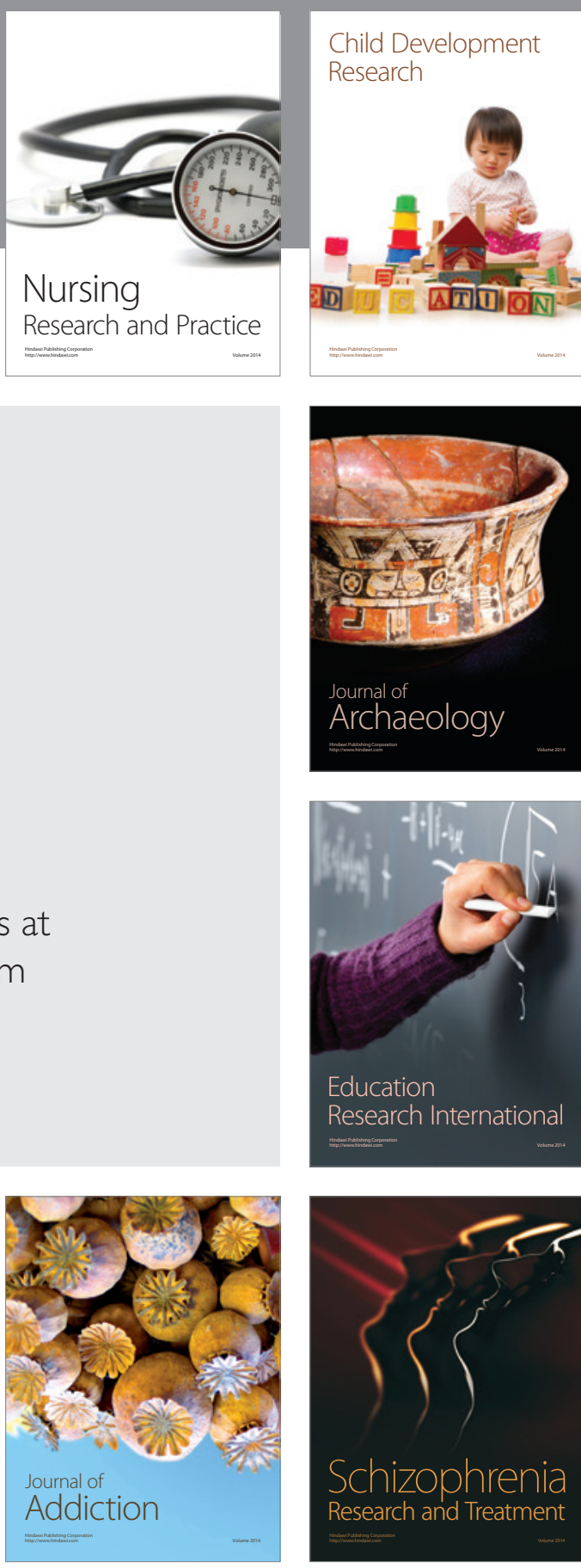

(D)
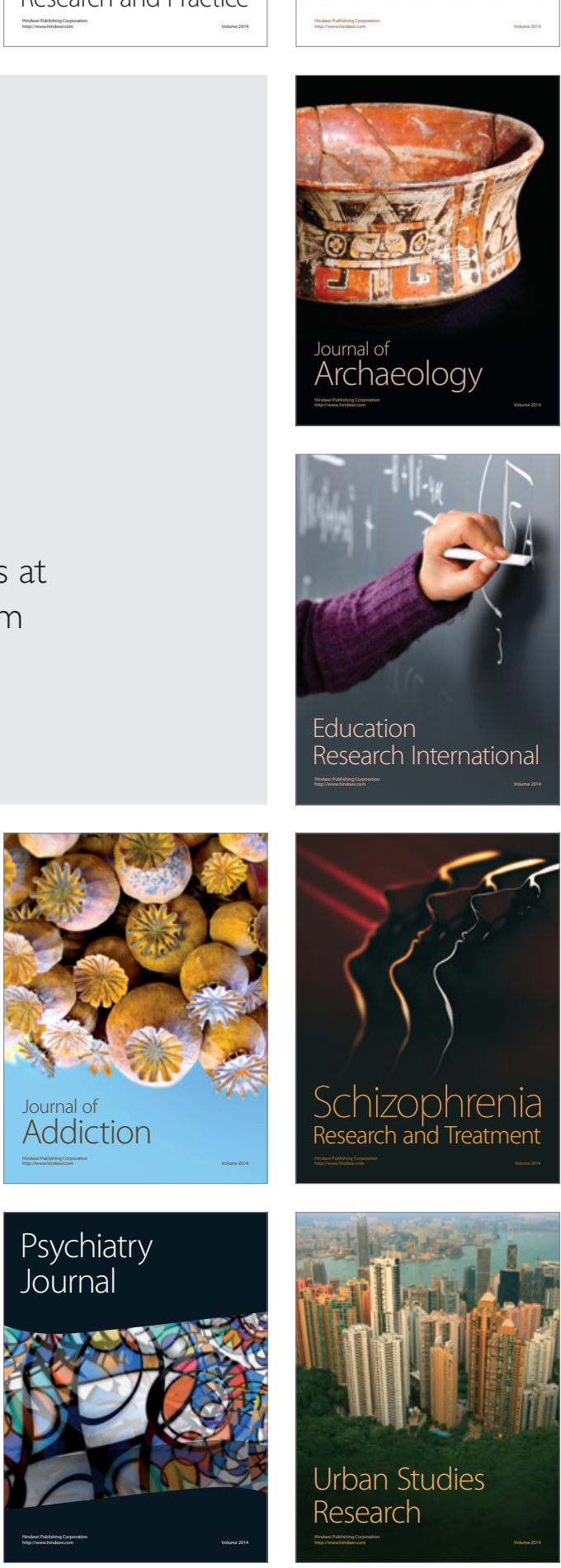